\title{
LIPOMA OF HAND AND FINGER: A 6 PATIENT CASE SERIES.
}

Prakash Kumar M.N ${ }^{1}$,Sowmya D2 ${ }^{2}$ Gautham M³ , Mir Mahir Ali ${ }^{4}$

\section{HOW TO CITE THIS ARTICLE:}

Prakash Kumar M.N, Sowmya D, Gautham M, Mir Mahir Ali. "Lipoma of Hand and Finger: A 6 Patient Case Series". Journal of Evolution of Medical and Dental Sciences 2014; Vol. 3, Issue 02, January 13; Page: 295-302, DOI:10.14260/jemds/2014/1824

ABSTRACT: INTRODUCTION: Lipoma, the ubiquitous benign tumor, is not very common in the hand and that to involving the palmar space or finger is very rare. This series of case presentation lays emphasis on consideration of lipoma in the differential diagnosis of swellings/ soft tissue tumors of the hand and the use of imaging studies in their diagnosis. We report a series of six cases of lipoma in different parts and planes of hand, involving palm and fingers. An uncommon site, size, shape, plane and age of occurrence of this common tumor warrants it's reporting and an effort had been made to highlight the management. CONCLUSION: Hand lipoma is rare entity for a surgeon in the differential diagnosis of soft tissue tumors with radiology being an invaluable tool. Though rare but frequently seen in this part of country, Precise surgical techniques with a sound anatomic knowledge helps in complete excision without damaging the vital structures and abates recurrences. KEYWORDS: Lipoma, subcutaneous, mid-palmar space.

INTRODUCTION: Lipomas are ubiquitous benign, mesenchymal neoplasms occurring in areas of abundant adipose tissue ${ }^{1}$. They are not frequently seen in the hand and those involving the fingers are very rare, with reported incidence of $1 \%{ }^{2}$.When it is noted in palm frequently found in thenar and hypothenar region, as described by Al Qattan et al.2005³.Stein et al in 1959 reported first patient with a lipoma of the finger ${ }^{4}$ and since then, 14 cases were identified in the literature that concerned lipoma case reports of the fingers ${ }^{5}$. Of those, totally 3 were on the index finger, 2 cases occurring distal to the right proximal interphalangeal joint and 1 case in the left index finger ${ }^{6}$, all of them posttraumatic in nature.

CASE PRESENTATION: We present six cases of lipoma: solitary, non-traumatic, three in palm and three in fingers two of which in index finger and one in ring finger, collected in our practice over a period of 2 years from July 2011 to august 2013, comprising of 2 male and 4 females, with average age group of about 43 years.

\section{CASE REPORTS:}

Case 1: A 51-year-old woman presented with progressive fullness in thenar region of the left hand since a year. She was right hand dominant without any history of trauma in the past. There was no history of smoking in the past and there were no other swellings elsewhere in the body. She complained of dull aching pain in this area, which aggravated when she tried to hold objects and this reduced the ability to grip. Examination revealed a solitary, smooth, soft, non-tender mass in the mid-palmar region (Fig.1)

MRI revealed a $2.3 \times 2.2 \times 2.9 \mathrm{~cm}$ lipoma situated in mid palmar space superficial to flexor tendons of $2^{\text {nd }}, 3^{\text {rd }}$ and $4^{\text {th }}$ finger, extending distally up to distal third of metacarpal bones and 


\section{ORIGINAL ARTICLE}

proximally up to distal margin of flexor retinaculum, without calcification and ossification points or bony infiltration (Fig.2).

Subsequently, the mass was removed surgically through palmar access, it was found in the mid-palmar space deep to the aponeuroses (Fig.3). After surgical excision, the lipoma measured $5.25 \times 5.50 \times 3.20 \mathrm{cms}$ in the largest dimensions. No infiltration into surrounding structures was seen. Post-operative period was uneventful (Fig-4), pathological examination of specimen confirmed lipoma without evidence of malignancy.

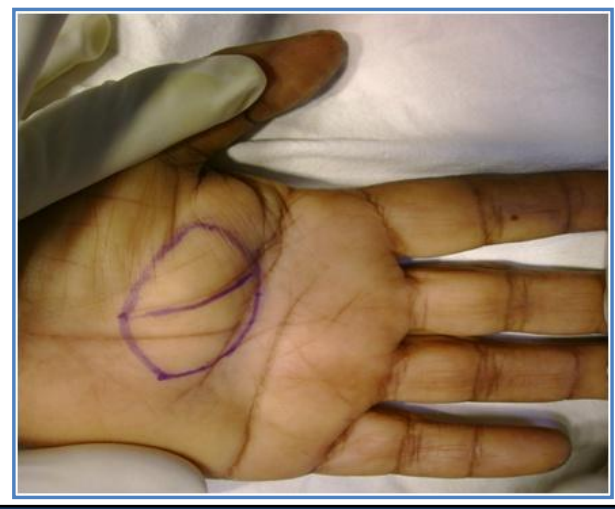

Fig. 1-Case 1: Mid-palmar space soft tissue swelling

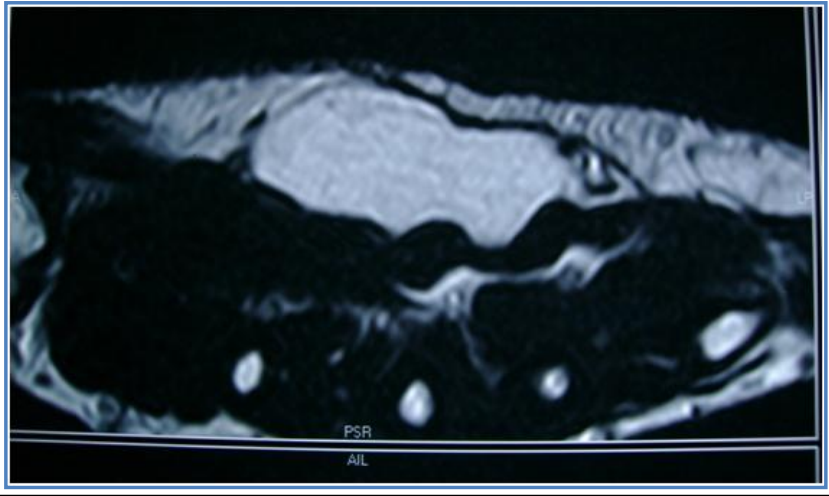

Fig. 2-Case 1: MRI showing lipoma above the flexor tendons (shown by indentation)

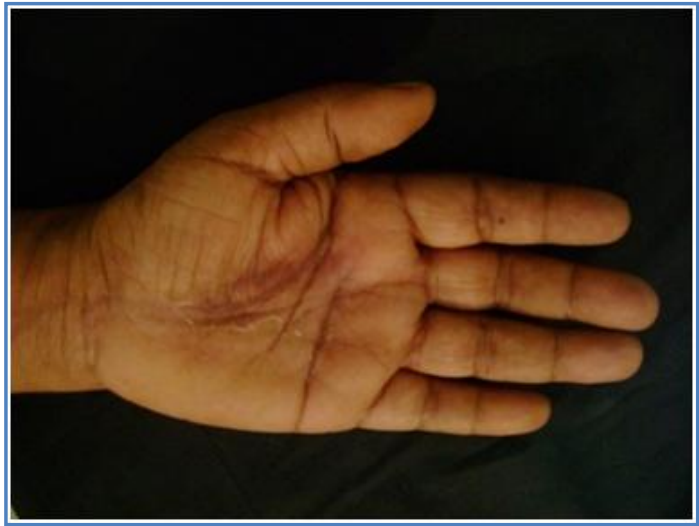

Fig. 4-Case 1: Post operative scar well settled

Case 2: A 42 years old female presented with mass in the right palm, over a period of 2 years, Mass had been a small lump which had significantly increased in size over the past 1 year. There was no history of smoking in the past and there were no other swellings elsewhere in the body, patient had no functional deficit, it did not interfere with her grasping ability, MRI revealed lipoma situated in mid palmar space. 
On examination there was a $3.0 \times 2.5 \mathrm{cms}$ mass, it was soft, nontender on palpation, sensation over palm and finger were normal. (Fig-5)

Excisional biopsy was planned, under axillary block, tourniquet was applied and palmar incision was made. A lobulated yellow mass was exposed, it was situated deep to palmar fascia, complete excision was done (Fig-6, 7), due to unyielding nature of palmar fascia after excision the actual size of lipoma was $3.5 \times 3.2$, post-operative period was uneventful, histopathological examination of specimen was that of lipoma.

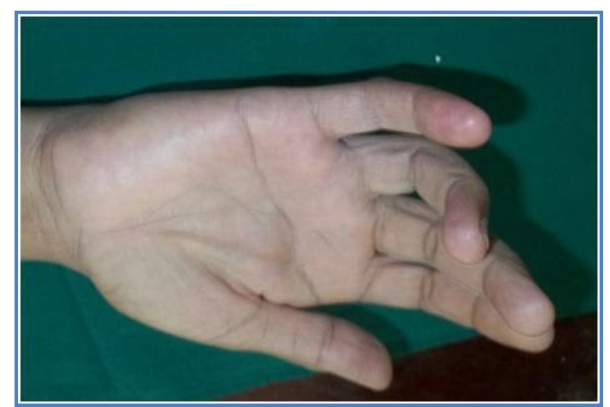

Fig. 5-Case 2: Pre operative photo showing swelling

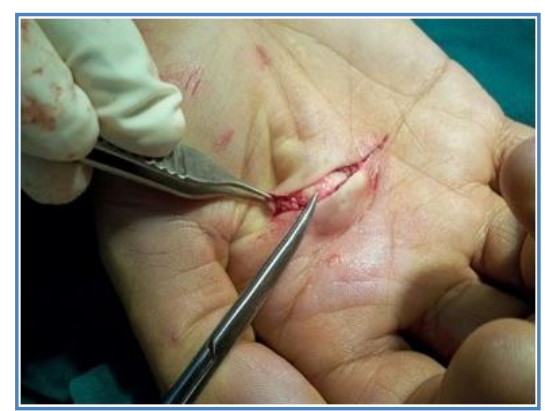

Fig. 6-Case 2: Showing crease incision

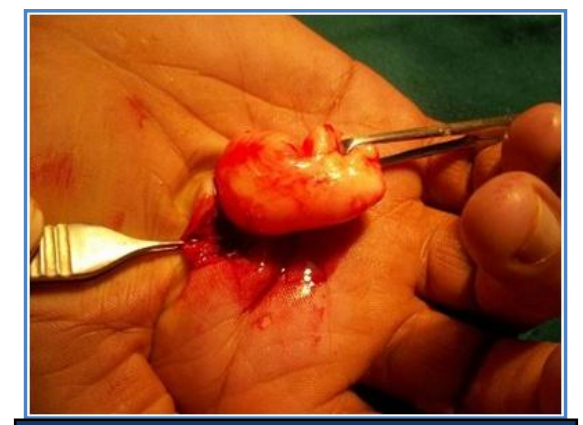

Fig. 7 - Case 2: Showing complete excision of lipoma

Case 3: A 40 year old male presented with h/o swelling in the left palm, over the third and fourth metacarpo-phalangeal joints, he had discomfort when using his hand for normal daily activities, no sensory disturbance distal to lesion. No history of traumaor any other lesions elsewhere in the body.

On examination a mass measuring $3.5 \times 3.5 \mathrm{cms}$, soft, nontender, smooth surface (Fig-8). Under regional anesthesia (Brachial block), incision was made, under loupe magnification meticulous dissection was done, neurovascular bundle was dissected out from the mass, lobulated yellowish mass was completely excised, post excision measurement of lipoma was, 4.2x3.8. Histopathological examination of mass was consistent with lipoma, post-operative period was uneventful. 


\section{ORIGINAL ARTICLE}

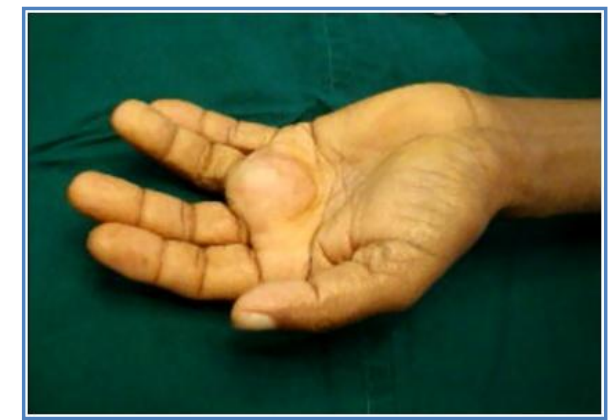

\section{Fig.8 - Case 3: Swelling over the $3^{\text {rd }}$ and $4^{\text {th }}$ MCP joint extending into web space}

Case 4: A 50 year old male presented with h/o difficulty in complete flexion of distal inter phalangeal joint of index finger. A solitary ill-defined swelling was noted on the medial aspect of index finger (Fig-9).

On examination a swelling $1.5 \times 1.5 \mathrm{cms}$ present over the medial aspect of index finger over the distal interphalangeal joint extending more towards volar aspect, soft in consistency smooth surface, nontender. No sensory disturbance distal to lesion. FNAC was consistent with lipoma.

Under digital block, hemostatic tourniquet was applied over the base of finger, mid lateral incision was made, subcutaneous yellowish lobulated mass was completely excised measuring 1.8x1.5, neurovascular bundle was meticulously dissected out from lesion (Fig-10), wound was closed primarily, pathological examination was consistent with lipoma.

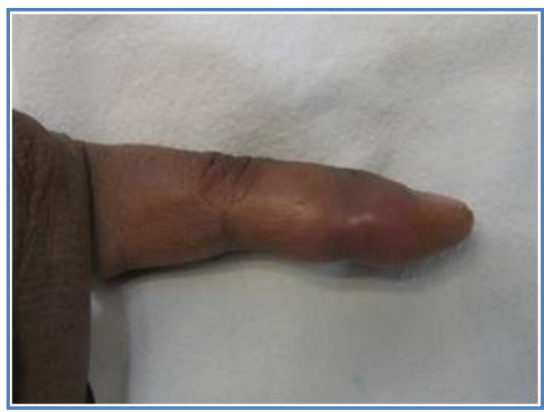

Fig. 9-Case 4: Illdefined swelling over the medial aspect of DIP joint of index finger

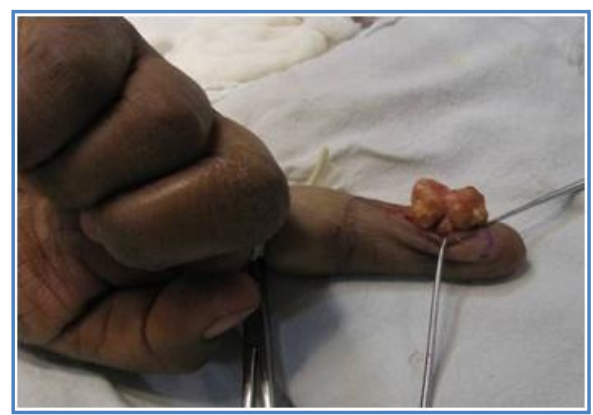

Fig.10-Case 4: Showing complete excision through mid lateral incision

Case 5: A 38 middle aged male presented with a swelling over index finger pulp over the past 1 and half years, gradually increasing in size, No history of trauma or any swelling elsewhere in the body, On examination $1 \mathrm{x} 1 \mathrm{cms}$ soft to firm in consistency, non-tender swelling over the pulp, (Fig-11), Under anesthesia and tourniquet control excisional biopsy was done by making mid lateral incision under loupe magnification, complete excision was done, HPE was consistent with fibrolipoma. 


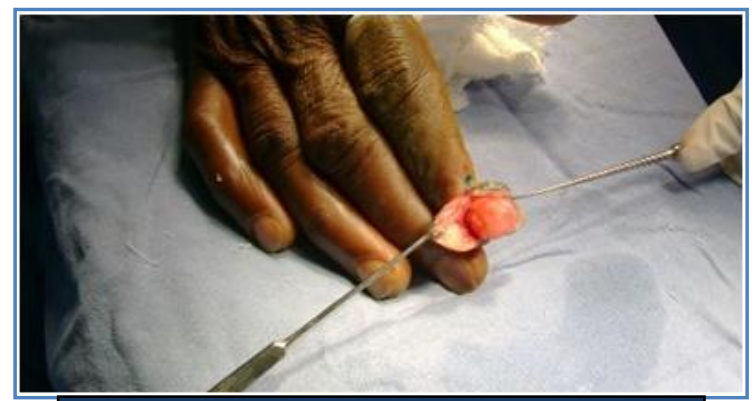

Fig. 11 - Case 5: Showing excision

of Right index finger Lipoma

Case 6: Thirty five years old female patient presented with a swelling in the right ring finger of five years duration.

She first noticed the swelling on the palmar aspect near the base of the ring finger about $1 \mathrm{x}$ $0.5 \mathrm{cms}$ in size which progressively increased to present size. She had no complaints of pain, sudden increase in size, secondary changes in the swelling, paresthesias, vascular complaints, limitations of joint movement.

Clinical examination revealed a butterfly shaped swelling occupying the volar and dorsal aspects of proximal phalanx of ring finger of the right hand. Vertically extending from $1 \mathrm{~cm}$ distal to the distal transverse palmar crease till the PIP crease measuring about $5.3 \times 6 \mathrm{cms}$.

This soft, mobile swelling was well above the plane of the tendon sheath without any features of neurovascular compression or limitation of movements. A working diagnosis of subcutaneous lipoma was made.

Soft tissue ultrasound showed the swelling to be above the tendon sheath. Patient was planned for surgery under transaxillary block with tourniquet control. A volar zig zag incision was made. The swelling was excised in toto. Operative exploration revealed a sub-cutaneous thyroid shaped lipoma, curving on either side of the volar surface of the finger, explaining it's near circumferential extension.

Both the neurovascular bundles were identified and preserved. Histological examination showed a yellowish, lobulated swelling of $6.5 \times 8.0 \times 4.6 \mathrm{cms}$ in the largest dimension, made of mature adipocytes. (Fig-12).

One year follow up revealed no recurrence and full range of movements of all joints.

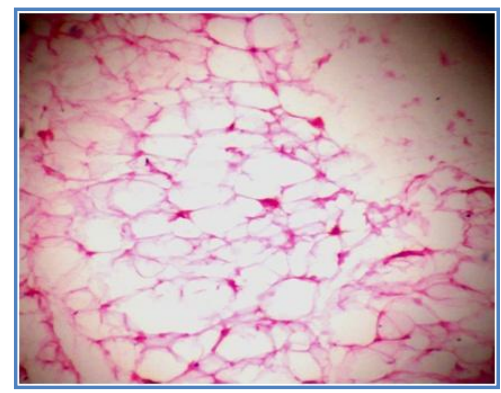

Fig. 12 - Case 6: Histopathological examination slide showing mature adipocytes. 
DISCUSSION: Lipomas appear mostly in the fifth and sixth decade and probably are the most common solid cellular hand tumors. They are seldom seen in the hand and are extremely rare in the digits ${ }^{1}$. Lipomas are benign soft tissue tumors accounting for approximately $16 \%$ of soft tissue mesenchymal tumors ${ }^{5}$.As mentioned previously lipomas in the digits have a reported incidence of only $1 \%{ }^{2}$.

Lipoma in the hand was classified by Manson as superficial and deep palmar lipoma; the deeper ones are less common than the superficial ones. Since the thick palmar fascia is strong, a lipoma may not be recognized although nerve compression symptoms may be gross ${ }^{7}$.

Clinically, superficial lipoma commonly appears as asymptomatic, slow growing, soft fluctuant, and bulging, lobulated and mobile mass. Because of their enlarging size, they may lead to limitation of mobility and impairment of grasping. Lateral deviation of the fingers also may be present when the tumor arises around the metacarpophalangeal joints. Most often presenting as a solitary mass, hand lipomas are often asymptomatic and only come to clinical attention when they are of cosmetic concern or become large enough to create mechanical impairment. In Leffert's series of 141 lipomas of the upper extremity, 109 tumors were asymptomatic and excised solely for aesthetic reasons. Of the 32 symptomatic lesions, 26 caused pain or tenderness, and 6 produced paresthesias or sensory deficit secondary to nerve compression. Similar symptomatic presentations have been documented extensively in the literature. Lipomas that restricted range of motion and deformed the wrist or digits, decreased grip strength, or caused muscle paralysis, polyarthritis, trigger finger, dysesthesias, muscle atrophy, and nail plate dystrophy and thinninghave been reported $^{8}$.

Etiology of lipoma remains unclear, variety of factors have been linked to the creation of lipomas, which includes trauma, obesity, hypercholesterolaemia9.

Clinical evaluation of superficial lipomas is accurate for diagnosis in up to $85 \%$ of cases ${ }^{10}$, contrary to deep lipomas for which clinical evaluation indicates only a nonspecific mass.

When subcutaneous, diagnosis can be made by a characteristic "doughy" feel on palpation. Application of an ice pack to the tumor to chill and harden the fat has also been used to aid in diagnosis ${ }^{8}$.

Radiological evaluation is diagnostic in up to $71 \%$ of cases of lipoma ${ }^{10}$. Ultrasound examination demonstrates a homogeneous and circumscribed hyper echoic areas 11,12.Computed tomography and especially magnetic resonance imaging are helpful in the assessment of such lesions. The MR images of such lesions reveals tissue that is isointense relative to subcutaneous fat, regardless of pulse sequences. When contrast is applied, the mass does not enhance except for its capsule. In $37-49 \%$ of cases CT or MR images reveal intrinsic thin septa $(<2 \mathrm{~mm})$, a sign that is considered almost pathognomonic for the diagnosis of lipoma ${ }^{13}$.

At the moment, MRI is the most reliable imaging method to diagnose lipomas. T1-weighted images show high signal intensity in a well-defined encapsulated even soft-tissue mass.

The main imaging criteria used to differentiate those lesions from their malignant counterparts, liposarcomas, is the absence of septa in most of the cases, the presence of mineralization areas best depicted with CT and the absence of interdigitations with skeletal muscle, a feature described only in intramuscular lipomas ${ }^{10}$.

If a space-occupying lesion is detected, MRI is useful to document exact site, size and its relation to neurovascular structure and it is radiological investigation of choice in this situation to 
delineate the relationship between the tumor and adjacent structures allowing the surgeon to plan the operation 14 .

Lipomas arising from the deep palmar space tend to present in the periphery of the hand because of the unyielding nature of the overlying palmar aponeuroses. Diagnosis in the hand and digits can be difficult, because of their rarity and deeper location. The differential diagnosis as mentioned includes other soft tissue tumors such as ganglion cysts, giant-cell tumors, myxomas, angiolipomas and intraneural lipofibromas ${ }^{6}$.

Most common indication for removal of lipoma is the disturbance in hand functionality and cosmetic appearance ${ }^{15}$.

Careful dissection under magnification is necessary during the surgical procedure in order to avoid recurrence by removing the tumor in toto. Complete surgical marginal excision is the treat of choice of deep lipomas (shelling out without opening the capsule) ${ }^{16}$.

Lipomas in the mid-palmar space are unusual and are deceptive in terms of size due to unyielding palmar fascia as was the situation in our first two cases. However there was no compression over the adjacent vital structures. Third case of lipoma was also found in palm but not much affected or constrained by palmar aponueroses.

The finger lipomas were unique in the following ways- two of them involving index finger and other one involving the, ring finger which is, massive size and its unique thyroid gland like shape.

Despite its various size and shape, none of our patients had any sensory impairment.

Superficial lipomas can be easily diagnosed clinically aided with soft-tissue ultrasound while MRI is the investigation of choice for deeper lipomas, both as a diagnostic tool and as a surgical aid.

All patients were discharged without complications. There were no signs of recurrence during follow-up varying from minimum 3 months to maximum 12 months.

CONCLUSION: Although common elsewhere, lipomas of the hand are rare entities with excellent prognosis after successful excision and a very limited risk of transformation to malignancy. Preoperatively, imaging is important to delineate the extent of the lesion and to assist in operative planning. We recommend MRI for its ability to discern tissue planes.

Deep palmar lipomas are rare, deceptively large and extensive. MRI scan is the investigation of choice to delineate the extent of the tumor and its relation with important structures.

The awareness of lipomas is imperative in the differential diagnosis from other soft tissue tumors of the hand or digit. A precise surgical technique with a sound anatomic knowledge helps in complete excision without damaging the vital structures and abates recurrences.

\section{REFERENCES:}

1. Calandruccio JH, Jobe MT: Campbell Operative Orthopaedics.Volume 4. 9th edition. Edited by Canale ST. St. Louis: Mosby-Year Book, Inc; 1998:3704-3705.

2. De Giorgi V, Salvini C, Sestini S, Alfaioli B, Carli P: Lipoma of the finger: A case report and differential diagnosis.Clin Exp Dermatol 2005, 30:439-440.

3. Al Qattan MM, Al Lazzam AM, Al Thunayan A et al: Classification of benign fatty tumours in the upper limb. HandSurg, 2005; 10(1):43-59. 
4. Stein AH Jr: Benign neoplastic and nonneoplastic destructive lesions in the long bones of the hand.Surg Gynecol Obstet 1959, 109:189-197.

5. Ersozlu S, Ozgur AF, Tandogan RH: Lipoma of the index finger.Dermatol Surg 2007, 33:382384.

6. Stuffer M, Thurner JE: Lipoma of the index digit-a rare location.Arch Orthop Trauma Surg 1995, 114:239-240.

7. Manson ML.Tumors of the hand. Surg Gynec Obstet.1937; 64:129-148.

8. Murphey MD, Caroll JF, Flemming DJ, Pope TL, Gannon FH, Kransdorf MJ: Benign Musculoskeletal Lipomatous Lesions.Radiographics 2004, 24:1433-1466.

9. Schrofft H, Hager D, Dunst KM, Huemer GM. Giant lipoma of thenar. Images in Clin Med 2007; 119(5-6):149.

10. Ohguri T, Aoki T, Hisaoka M, Watanabe H, Nakamura K, Hashimoto H, Nakamura T, Nakata $\mathrm{H}$ : Differential diagnosis of benign peripheral lipoma from well-differentiated liposarcoma on MR imaging: is comparison of margins and internal characteristics useful?

11. James JJ, Robin A, Wilson M, Evans AJ. The Breast. In: Adam A, eds. Grainger and Allisons Diagnostic Radiology. $5^{\text {th }}$ ed. Phliadelphia, Pa: Elsevier; 2008.

12. Pant R, Poh AC, Hwang SG: An unusual case of an intramuscular lipoma of the pectoralis major muscle simulating a malignant breast mass. Ann Acad Med Singapore.2005; 34(3):275-6.

13. Posch JL: Tumors of the hand. J Bone Joint Surg Am. 1956; 38-A (3):517-39; discussion 539-540.

14. Lee YH, Jung JM, Baek GH, Chung MS: Intramuscularlipoma in the thenar or hypothenar muscles. Hand Surgery, 2004; 9:49-54.

15. Higgs PE, Young VL, Schuster R, Weeks PM: Giant lipomas of the hand and forearm. South Med J, 1993; 86(80):887-890.

16. Billing V, Mertens F, Domanski HA, Rydholm A: Deep-seated ordinary and atypical lipomas, J Bones Joint Surg Br 2008; 90:929-33.

\section{AUTHORS:}

1. Prakash Kumar M.N.

2. Sowmya D.

3. Gautham M.

4. Mir Mahir Ali

\section{PARTICULARS OF CONTRIBUTORS:}

1. Plastic Surgeon, Department of Plastic Surgery, ESI- Post Graduate Institute of Medical Sciences and Research, Rajajinagar, Bangalore.

2. Resident, Department of Plastic Surgery, ESIPost Graduate Institute of Medical Sciences and Research, Rajajinagar, Bangalore.

3. Plastic Surgeon, Department of Plastic Surgery, ESI- Post Graduate Institute of Medical Sciences and Research, Rajajinagar, Bangalore.
4. Senior Resident, Department of Plastic Surgery, ESI- Post Graduate Institute of Medical Sciences and Research, Rajajinagar, Bangalore.

\section{NAME ADDRESS EMAIL ID OF THE CORRESPONDING AUTHOR:}

Dr. Prakash Kumar M.N.,

No.-11, Chennakeshava Nilaya, $1^{\text {st }}$ Floor, $2^{\text {nd }}$ Cross, Srirampuram, Bangalore - 560021.

Email -pritamprakash97@yahoo.co.in

Date of Submission: 01/01/2014. Date of Peer Review: 02/01/2014.

Date of Acceptance: 06/01/2014.

Date of Publishing: 08/01/2014. 